\title{
Identification of uncommon oral yeasts from cancer patients by MALDI-TOF mass spectrometry
}

Narges Aslani ${ }^{1,2}$, Ghasem Janbabaei ${ }^{3}$, Mahdi Abastabar ${ }^{2}$, Jacques F. Meis ${ }^{4,5}$ (D) Mahasti Babaeian³, Sadegh Khodavaisy ${ }^{6}$, Teun Boekhout ${ }^{7,8}$ and Hamid Badali ${ }^{2,9^{*}}$ (D)

\begin{abstract}
Background: Opportunistic infections due to Candida species occur frequently in cancer patients because of their inherent immunosuppression. The aim of the present study was to investigate the epidemiology of yeast species from the oral cavity of patients during treatment for oncological and haematological malignancies.

Methods: MALDI-TOF was performed to identify yeasts isolated from the oral cavity of 350 cancer patients. Moreover, antifungal susceptibility testing was performed in according to CLSI guidelines (M27-A3).

Results: Among 162 yeasts and yeast-like fungi isolated from the oral cavity of cancer patients, Candida albicans was the most common species (50.6\%), followed by Candida glabrata (24.7\%), Pichia kudriavzevii (Candida krusei (9.9\%)), Candida tropicalis (4.3\%), Candida dubliniensis (3.7\%), Kluyveromyces marxianus (Candida kefyr (3.7\%)) and Candida parapsilosis (1\%). In addition, uncommon yeast species i.e., Saprochaete capitata, Saccharomyces cerevisiae, Clavispora lusitaniae (C. Iusitaniae) and Pichia kluyveri (C. eremophila) were recovered from oral lesions. Oral colonization by C. albicans, non-albicans Candida species and uncommon yeasts were as follow; 55\%, 44\% and 1\%, whereas oral infection due to C. albicans was 33.3\%, non-albicans Candida species 60.6\%, and uncommon yeasts $6.1 \%$. Poor oral hygiene and xerostomia were identified as independent risk factors associated with oral yeast colonization. The overall resistance to fluconazole was 11.7\% (19/162). Low MIC values were observed for anidulafungin for all Candida and uncommon yeast species.

Conclusions: This current study provides insight into the prevalence and susceptibility profiles of Candida species, including emerging Candida species and uncommon yeasts, isolated from the oral cavity of Iranian cancer patients. The incidence of oral candidiasis was higher amongst patients with hematological malignancies. The majority of oral infections were caused by non-albicans Candida species which were often more resistant to anti-fungal agents. Our findings suggest that anidulafungin should be used as antifungal of choice for prophylaxis in clinically high-risk patients with documented oral colonization or infection.
\end{abstract}

Keywords: MALDI-TOF MS, Candida species, Oral cavity, Cancer patients

\footnotetext{
* Correspondence: badalii@yahoo.com

2Department of Medical Mycology and Parasitology, School of Medicine,

Mazandaran University of Medical Sciences, Sari, Iran

${ }^{9}$ Invasive Fungi Research Center (IFRC), School of Medicine, Mazandaran

University of Medical Sciences, Sari, Iran

Full list of author information is available at the end of the article
} 


\section{Background}

Worldwide the incidence of mild to severe fungal infections (FI) has dramatically increased in the last several decades, especially in patients infected with human immunodeficiency virus (HIV), those that prolongedly use broadspectrum antibiotics, patients undergoing hematopoietic stem cell transplantation (HSCT), and those receiving intensive chemo- and /or radiotherapy $[1,2]$. The latter factors are important, not only because of the cytotoxic effects they have on mucosal immune defense mechanisms, but also because they change the physiology and microbial ecology of the oral environment to prolonged xerostomia and hyposalivation leading to intra-oral colonization, thus facilitating overgrowth of fungal pathogens leading to significant patient morbidity $[2,3]$. The most predominant yeasts isolated from oral colonization and infection are Candida species that are the most important opportunistic fungal pathogens in humans and cause mucosal to deepseated candidiasis [4]. The incidence of oral colonization and infection has been reported to be $43 \%$ to $90 \%$ and $13 \%$ to $52 \%$ among cancer patients, respectively, and involves the mouth cavity and surrounding soft tissue, followed by pain, erythema, ulceration, quantitative and qualitative salivary changes and taste disorders [5, 6]. Studies have demonstrated that Candida albicans (78\%) is predominantly involved in oral mucositis. The species remains a major source of illness during immunosuppression despite the application of antifungal therapy and can cause a systemic infection associated with significant morbidity and mortality rates [3, 7]. Although $C$. albicans is responsible for the vast majority of oral colonizations and infections, non-albicans Candida species belong to diverse species complexes, i.e., Candida parapsilosis, Candida glabrata, Candida tropicalis, Kluyveromyces marxianus (Candida kefyr), Pichia kudriavzevii (Candida krusei), Meyerozyma guilliermondii (Candida guilliermondii) and other uncommon yeast species with a reduced susceptibility to triazoles and echinocandins become a serious clinical challenge and thus the isolates need to be properly identified [8-12]. Little is known about the etiological importance of yeasts in oral colonization and infection among Iranian cancer patients. Identification using DNA barcodes, is time consuming, expensive and sometimes unspecific for cryptic species. Matrix-assisted laser desorption/ionization time-of-flight mass spectrometry (MALDI-TOF MS) is an important technique for the rapid and reliable identification of species with sufficient specificity, reproducibility and sensitivity [13, 14]. Herein, we investigated the prevalence of Candida species and uncommon yeasts responsible for colonizing and infecting the oral cavity of patients with different types of cancer using MALDI-TOF MS for identification. Moreover, guidelines for the treatment of candidiasis have approved the use of polyenes, azoles and echinocandins $[15,16]$. Notably, in recent years, highly elevated MICs to antifungals, especially fluconazole, have appeared and antifungal drug resistance is quickly becoming a serious concern, especially when immunological defenses are impeded. In vitro antifungal susceptibility tests have an important role in surveillance of resistance and are also beneficial for choosing the right antifungal agents to be used for treatment. It seems that non-albicans Candida strains show considerable emergence of resistance to antifungal drugs $[10,17,18]$. Limited data on the in vitro antifungal susceptibility patterns against isolates of Candida species from the oral cavity of patients with oncological and hematological malignancies are available. Therefore, in vitro antifungal susceptibilities were determined against 162 clinically isolates of Candida species and uncommon other yeast species from Iranian cancer patients.

\section{Methods}

This study was performed at the cancer center of the Mazandaran University Hospital that has 1600 oncology and hematology in-patient admissions per year. All patients were required to sign an informed consent form prior to entry into the study. During one year 350 oral swab samples were randomly obtained from Iranian cancer patients undergoing intensive chemotherapy, namely $210(60 \%)$ males and 140 (40\%) females and ranging 17-88 years in age with and without sign and symptoms of oral infection, including white plaque, erythematous and ulcerative lesions, dryness, pain, altered taste sensation and halitosis. Demographic data on age, gender, oral hygiene, type of cancer, history of prior fungal infections, use of topical or systemic antifungal therapy, prophylaxis and medications were collected at enrolment.

\section{Study design and clinical specimens}

As oral examination, signs and symptoms of inflammation suggestive of oral candidiasis were documented and included soreness, erythema, ulceration and the presence or absence of white plaques in the mouth. Specimens were obtained by sterile cotton swabs moistened with normal saline that were placed on the tongue, buccal mucosa and labial sulcus, transported in sterile tubes and were examined initially in $10 \% \mathrm{KOH}$, followed by inoculation on malt extract agar (MEA, Difco) supplemented with chloramphenicol and CHROMagar Candida medium (CHROMagar Company, Paris, France) to ensure purity, and incubated at $37{ }^{\circ} \mathrm{C}$ for $24 \mathrm{~h}$. Strains were preliminarily identified using conventional methods, i.e., germ tube tests, formation of pseudohyphae, production of chlamydospores and carbohydrate assimilation tests using the ID 32 C kit (bioMérieux, Marcy l'Etiole, France). Oral yeast colonization was defined as presence of yeasts in the oral cavity. Oral candidiasis was defined as presence 
of Candida species in the oral cavity together with symptoms and signs of inflammation / mucositis and / or presence of white plaques.

\section{Fungal species identification}

Subsequently, genomic DNA was extracted from all test isolates along with reference strains as described by $\mathrm{Xu}$ et al. and stored at $-80^{\circ} \mathrm{C}$ prior to use [19]. All strains were identified by PCR-RFLP and using the amplified HWP1 gene to distinguish members of the $C$. albicans complex as previously described [20]. Cultures of Candida isolates were preserved at $-70{ }^{\circ} \mathrm{C}$ at the reference culture collection of invasive fungi research center (IFRC, Sari, Iran) using cryo-tubes (Mast Diagnostics, Bootle, Merseyside, UK) until further analysis.

MALDI-TOF MS-based identification of all yeast and yeast-like isolates was performed according to Bruker Daltonics (Bremen, Germany) with the ethanol (EtOH)/ formic acid (FA) extraction protocol. For extraction, two loops of yeast biomass (1- $\mu$ volume, sterile inoculation loop) not older than $24 \mathrm{~h}$ growing on Sabouraud Dextrose Agar (SDA) were suspended in $300 \mu \mathrm{l}$ of molecular graded ionized water and further processed with $900 \mu \mathrm{l}$ of $95 \%$ $\mathrm{EtOH}$. A volume of $25 \mu \mathrm{l}$ of FA was found to be optimal and an equal volume of acetonitrile $(\mathrm{ACN})$ was added later. From the crude protein extract of each tested strain, $1 \mu \mathrm{l}$ was spotted onto steel target plate (Bruker Daltonics) and allowed to dry at room temperature. Bacterial test standard (Bruker Daltonics) was used as a positive control. Before measurements, all tested spots were overlaid with $1 \mu \mathrm{l}$ of alpha-cyano-4- hydroxycinnamic acid (Bruker Daltonics) saturated matrix solution. The yeast identification was operated by the MALDI Biotyper 3.0 system based on mass spectra generated with the Microflex LT software and compared with two databases simultaneously. Identification scores were interpreted according to the manufacturer's recommended criteria: a log score value $>2.0$ indicated correct identification to the species level, a $\log$ score $1.999>$ value $>1.7$ correct genus recognition, and no reliable identification with a score $<1.7$. Each isolate was considered correctly identified if at least one of the duplicates gained scores $>2$. Strains with results $<2.0$ or no peaks found were retested from a fresh culture. The identification was also considered correct if at least one spot from the duplicate gave a reliable identification with score $>1.7$ that was concordant with the sequencing results $[21,22]$.

\section{Antifungal susceptibility testing}

Antifungal susceptibility testing was carried out using the Clinical and Laboratory Standards Institute broth microdilution method (CLSI), following the M27-A3 and M27-S4 guidelines [23, 24]. Amphotericin B (AMB; Sigma, St. Louis, MO, USA), fluconazole (FLU; Pfizer, Groton, CT,
USA), caspofungin (CFG; Merck Sharp and Dohme BV, Haarlem, The Netherlands) and anidulafungin (AFG; Pfizer) were dissolved in $1 \%$ dimethyl sulfoxide (DMSO, Sigma) and were prepared at a final concentration of $0.016-16 \mu \mathrm{g} / \mathrm{ml}$ for amphotericin B; $0.063-64 \mu \mathrm{g} / \mathrm{ml}$ for fluconazole, and $0.008-8 \mu \mathrm{g} / \mathrm{ml}$ for caspofungin and anidulafungin. RPMI 1640 medium with glutamine without bicarbonate (Sigma) buffered to $\mathrm{pH} 7$ with $0.165 \mathrm{~mol} / \mathrm{l}$ 3N-morpholinepropanesulfonic acid (MOPS; Sigma) was used. Drug-free and yeast-free controls were included, and microtiter plates were incubated at $35{ }^{\circ} \mathrm{C}$ and read visually after $24 \mathrm{~h}$, as validated recently by Pfaller et al. $[25,26]$. Pichia kudriavzevii (= C. krusei) ATCC 6258 and Candida parapsilosis ATCC 22019 were used as quality control strains. Except for amphotericin B, the MIC endpoints for all antifungals were defined as the lowest drug concentration that caused $50 \%$ growth inhibition vis-à-vis the drugfree controls. The MIC for amphotericin B was defined as the lowest concentration at which there was $100 \%$ inhibition of growth.

\section{Statistical analysis}

Statistical analyses were performed using SPSS (version 24.0; Windows, Chicago, IL, USA) and R Software (version 3.0.1). Binary and bayesian logistic regression were used to model the effect of risk factors on colonization. $P$ values of $<0.05$ were considered statistically significant.

\section{Results}

Demographic, clinical information and types of cancers in the study population are summarised in Table 1 . In total, we collected $162(46.3 \%)$ strains of yeasts and yeast-like fungi from 350 cancer patients undergoing intensive chemotherapy. The mean age of the patients was 53 years (range 17-88 years). Among the patients, males comprised $58.6 \%(95 / 162)$ and females $41.4 \%(67 / 162)$. Nearly half ( $n$ $=83,51.2 \%)$ of the patients suffered from different types of lymphoma, 18 (11\%) had colorectal cancer, 13 (8\%) lung cancer, 13 (8\%) gastric cancer, 10 (6.2\%) breast cancer, and 25 (15.4\%) other solid tumors (i.e. liver, kidney, nasopharyngeal, prostate, esophagus, cervical, uterus and ovaries cancer). The age of the majority of cancer patients ranged from 41 to 60 (51/162). A logistic regression analysis identified xerostomia and poor oral hygiene as independent risk factors associated with oral yeast colonization (Table 2). Oral yeast colonization was prevalent in $79.6 \%(129 / 162)$ of all cancer patients and $20.4 \%$ (33/162) of those had clinical and microbiological evidence of oral candidiasis. Type of cancer and the number of chemotherapy sessions showed a statistical significant risk for the development oral infection. Figure 2 shows that increasing the number of chemotherapy sessions of cancer patients, correlated with the presence oral candidiasis. Oral yeast colonization varied amongst different cancer types and was high in solid 
Table 1 Demographic and clinical description of Iranian cancer patients with oral colonization or infection

\begin{tabular}{|c|c|c|c|c|c|c|}
\hline \multirow[t]{2}{*}{ Cancer Type } & \multicolumn{2}{|l|}{ Count } & \multirow{2}{*}{$\begin{array}{l}\text { Candidiasis / } \\
\text {-Colonization }\end{array}$} & \multicolumn{2}{|l|}{ Species } & \multirow[t]{2}{*}{ Prophylaxis } \\
\hline & Total (\%) & $\operatorname{Sex}(M / F)$ & & Anamorph & Teleomorph & \\
\hline Basal Cell Carcinoma & $1(0.6 \%)$ & $0 / 1$ & $0 / 1$ & C. albicans (1) & Unknown & 1 \\
\hline \multirow[t]{2}{*}{ Breast Cancer } & \multirow[t]{2}{*}{$10(6.1 \%)$} & \multirow[t]{2}{*}{$0 / 10$} & \multirow[t]{2}{*}{$3 / 7$} & C. albicans (9) & - & \multirow[t]{2}{*}{1} \\
\hline & & & & C. krusei (1) & Pichia kudriavzevii (1965) & \\
\hline Bronchial Adenoma & $1(0.6 \%)$ & $1 / 0$ & $0 / 1$ & C. albicans (1) & - & - \\
\hline $\begin{array}{l}\text { Congestive Heart } \\
\text { Failure }\end{array}$ & $1(0.6 \%)$ & $0 / 1$ & $0 / 1$ & C. albicans (1) & - & - \\
\hline \multirow[t]{5}{*}{ Colorectal Cancer } & \multirow[t]{5}{*}{$18(11.1 \%)$} & \multirow[t]{5}{*}{$9 / 9$} & \multirow[t]{5}{*}{$3 / 15$} & C. albicans (7) & - & \multirow[t]{5}{*}{1} \\
\hline & & & & C. glabrata (5) & Unknown & \\
\hline & & & & C. kefyr (3) & $\begin{array}{l}\text { Kluyveromyces marxianus } \\
\text { (1971) }\end{array}$ & \\
\hline & & & & C. dubliniensis (2) & Unknown & \\
\hline & & & & C. Iusitaniae (1) & Clavispora lusitaniae & \\
\hline $\begin{array}{l}\text { Nasopharyngeal } \\
\text { Cancer }\end{array}$ & $1(0.6 \%)$ & $1 / 0$ & $1 / 0$ & C. albicans (1) & - & - \\
\hline \multirow[t]{3}{*}{ Esophagus Cancer } & \multirow[t]{3}{*}{$6(3.7 \%)$} & \multirow[t]{3}{*}{$2 / 4$} & \multirow[t]{3}{*}{$0 / 6$} & C. glabrata (3) & - & \multirow[t]{3}{*}{-} \\
\hline & & & & C. albicans (2) & - & \\
\hline & & & & C. krusei (1) & $\begin{array}{l}\text { Pichia kudriavzevii } \\
\text { (1965) }\end{array}$ & \\
\hline \multirow[t]{5}{*}{ Gastric Cancer } & \multirow[t]{5}{*}{$13(8.0 \%)$} & \multirow[t]{5}{*}{$8 / 5$} & \multirow[t]{5}{*}{$2 / 11$} & C. albicans (8) & - & \multirow[t]{5}{*}{2} \\
\hline & & & & C. glabrata (2) & - & \\
\hline & & & & C. dubliniensis (1) & - & \\
\hline & & & & C. tropicalis (1) & Unknown & \\
\hline & & & & Saprochata capitata (1) & Unknown & \\
\hline Hepatocellular & $5(3.1 \%)$ & $2 / 3$ & $1 / 4$ & C. albicans (3) & - & 1 \\
\hline & & & & C. glabrata (2) & - & \\
\hline Renal Cell Carcinoma & $1(0.6 \%)$ & $1 / 0$ & $0 / 1$ & C. albicans (1) & - & - \\
\hline Lung Carcinoma & $13(8.0 \%)$ & $10 / 3$ & $3 / 10$ & C. albicans (10) & - & - \\
\hline & & & & C. glabrata (3) & - & \\
\hline Lymphoma & $83(51.2 \%)$ & $57 / 26$ & $20 / 63$ & C. albicans (32) & - & 16 \\
\hline & & & & C. glabrata (22) & - & \\
\hline & & & & C. krusei (14) & Pichia kudriavzevii (1965) & \\
\hline & & & & C. tropicalis (6) & - & \\
\hline & & & & C. dubliniensis (3) & - & \\
\hline & & & & C. kefyr (3) & $\begin{array}{l}\text { Kluyveromyces marxianus } \\
\text { (1971) }\end{array}$ & \\
\hline & & & & C. eremophila (1) & Pichia kluyveri & \\
\hline & & & & C. parapsilosis (1) & Unknown & \\
\hline & & & & C. robusta (1) & Saccharomyces cerevisiae & \\
\hline $\begin{array}{l}\text { Nasopharyngeal } \\
\text { Cancer }\end{array}$ & $2(1.2 \%)$ & $2 / 0$ & $0 / 2$ & C. glabrata (2) & - & - \\
\hline Pancreatic Cancer & $1(0.6 \%)$ & $1 / 0$ & $0 / 1$ & C. albicans (1) & - & - \\
\hline Prostate Cancer & $1(0.6 \%)$ & $1 / 0$ & $0 / 1$ & C. albicans (1) & - & - \\
\hline Sarcoma & $1(0.6 \%)$ & $1 / 0$ & $0 / 1$ & C. glabrata (1) & - & - \\
\hline Uterine Cancer & $4(2.5 \%)$ & $0 / 4$ & $0 / 4$ & C. albicans (4) & - & - \\
\hline Total & $162(\approx 100 \%)$ & $95 / 67$ & $33 / 129$ & C. albicans (82) & - & 22 \\
\hline
\end{tabular}


Table 1 Demographic and clinical description of Iranian cancer patients with oral colonization or infection (Continued)

\begin{tabular}{|c|c|c|c|c|c|c|}
\hline \multirow[t]{2}{*}{ Cancer Type } & \multicolumn{2}{|l|}{ Count } & \multirow{2}{*}{$\begin{array}{l}\text { Candidiasis / } \\
\text {-Colonization }\end{array}$} & \multicolumn{2}{|l|}{ Species } & \multirow[t]{2}{*}{ Prophylaxis } \\
\hline & Total (\%) & $\operatorname{Sex}(M / F)$ & & Anamorph & Teleomorph & \\
\hline & & & & C. glabrata (40) & - & \\
\hline & & & & C. krusei (16) & Pichia kudriavzevii (1965) & \\
\hline & & & & C. tropicalis (7) & - & \\
\hline & & & & C. dubliniensis (6) & - & \\
\hline & & & & C. kefyr (6) & $\begin{array}{l}\text { Kluyveromyces marxianus } \\
\text { (1971) }\end{array}$ & \\
\hline
\end{tabular}

tumor patients (colonization rate 40.7\%) compared with patients with hematological malignancies (38.9\%). Patients with hematological malignancies had a higher rate of oral infection (12.3\%) than those with solid tumors (8\%) (Table 1). Figure 1 shows the results of identification based on conventional and molecular tests and their concordance at genus and species levels with MALDI-TOF assessments. Conventional and molecular methods identified 144 isolates as $C$. albicans $(n=82), C$. dubliniensis $(n=6), C$. glabrata $(n=40)$ and P. kudriavzevii $(=$ C. krusei, $n=16)$. The species distribution belonging to the oral colonization was $C$. albicans $(n=71), C$. dubliniensis $(n=4), C$. glabrata $(n=32), P$. kudriavzevii (C. krusei) $(n=11)$ and unknown species $(\mathrm{n}=11)$. Overall $C$. albicans $(\mathrm{n}=11), C$. dubliniensis $(n=2), C$. glabrata $(\mathrm{n}=8), P$. kudriavzevii (C. krusei) ( $n$ $=5)$ and unknown species $(n=7)$ causes of oral candidiasis were identified by conventional and molecular tests (Fig. 1). Among the $C$. albicans complex, neither $C$. stellatoidea nor $C$. africana were identified by HWP1 gene amplification. Subsequently, all isolates and the remaining 18 unknown isolates were identified and confirmed with MALDI-TOF at the species level. Our data showed that MALDI-TOF MS correctly identified 100\% isolates with score $>2.0$, indicating a secure genus and species identification. Isolates with scores of $>2.0$ comprised four genera and 11 species. Among the 162 isolates, MALDI-TOF MS identified 7 isolates ( $4.3 \%$ of all yeast isolates) as C. tropicalis, 6 (3.6\% of all yeast isolates) as K. marxianus (= C. kefyr) and 1 isolate as $C$. parapsilosis, which were not detected by the conventional and PCR-RFLP based identification methods. Overall C. glabrata $(n=40,24.7 \%)$, followed by P. kudriavzevii (C. krusei) ( $n=16,9.9 \%)$ were the most frequent leading agent of non-albicans Candida species among cancer patients. Overall $47.5 \%$ of patients $(n=77)$ were colonized or infected by non-albicans Candida species. In addition, MALDI-TOF MS identified $(n=4,2.5 \%$

Table 2 Logistic regression analysis of risk factors for oral yeast colonization

\begin{tabular}{llll}
\hline Risk factors & $P$-value & Odds ratio & $95 \% \mathrm{Cl}$ \\
\hline Xerostomia & 0.019 & 4.994 & $1.288-18.452$ \\
$\begin{array}{l}\text { Poor oral } \\
\text { hygiene }\end{array}$ & 0.014 & 2.734 & $1.207-6.261$ \\
\hline
\end{tabular}

of cancer patients) isolates as rarely uncommon yeasts, i.e., Saprochaete capitata, Saccharomyces cerevisiae, Clavispora lusitaniae (= C. lusitaniae) and Pichia kluyveri (= C. eremophila), which were not detected by the PCR-RFLP method. Uncommon yeast species that colonized the oral cavity of cancer patients were C. lusitaniae and S. cerevisiae, while $S$. capitata and P. kluyveri were found in oral infection (Fig. 1). The majority of cancer patients were colonized or infected by a single yeast species, but $4.9 \%(n=$ 8) of patients had two different species present. Only patients who developed infection were given antifungal medications. Of these, 22 (13.6\%) received prophylaxis with fluconazole $(200 \mathrm{mg} / \mathrm{kg} / \mathrm{d}$ for 7-14 days) and if clinical cure was not achieved in 14 days, the dose was increased up to $400 \mathrm{mg} / \mathrm{d}$. All these 22 patients had persistent candidiasis and were culture positive for Candida species $(C$. albicans $n=7$, P. kudriavzevii (C. krusei) $n=5, C$. dubliniensis $n=3, C$. glabrata $\mathrm{n}=3$, and one isolate of $K$. marxianus (C. kefyr), C. tropicalis, S. capitata and P. kluyveri).

\section{Antifungal susceptibility profiles}

The in vitro susceptibility data and the MIC distribution are presented in Tables 3 and 4. A total of 162 isolates of Candida species and uncommon yeasts were analyzed for their susceptibility to fluconazole, amphotericin B, caspofungin and anidulafungin. Fluconazole exhibited no activity against $15.9 \%(n=13)$ of $C$. albicans isolates ( $\mathrm{MIC}$ of 16 to $>64 \mu \mathrm{g} / \mathrm{ml}$ ), whereas the remaining 69 isolates revealed a MIC range of $0.063-8 \mu \mathrm{g} / \mathrm{ml}$. Notably, $12.5 \%$ of $C$. glabrata isolates $(n=5)$ showed fluconazole MICs of $>64 \mu \mathrm{g} / \mathrm{ml}$. All tested $C$. albicans isolates had low MICs of amphotericin B ( $\mathrm{MIC}_{50}$ values of $\left.1 \mu \mathrm{g} / \mathrm{ml}\right)$ but $35.4 \%(n=29)$ of $C$. albicans isolates had markedly elevated amphotericin B MICs ranging from 2 to $16 \mu \mathrm{g} /$ $\mathrm{ml}$. Moreover, elevated geometric means (GM) were observed for caspofungin $(0.34 \mu \mathrm{g} / \mathrm{ml})$ in comparison to anidulafungin $(0.06 \mu \mathrm{g} / \mathrm{ml})$. Notably, 35\% $(n=14)$ of the C. glabrata, $15.9 \%(n=13)$ of the C. albicans and $75 \%$ ( $n=12$ ) of the P. kudriavzevii (C. krusei) isolates revealed MICs of $\geq 1 \mu \mathrm{g} / \mathrm{ml}$ to caspofungin. Overall $27.8 \%$ of Candida species and uncommon yeasts revealed MICs of $\geq 1 \mu \mathrm{g} / \mathrm{ml}$ to caspofungin. All isolates showed reduced MICs to anidulafungin with MICs ranging from 


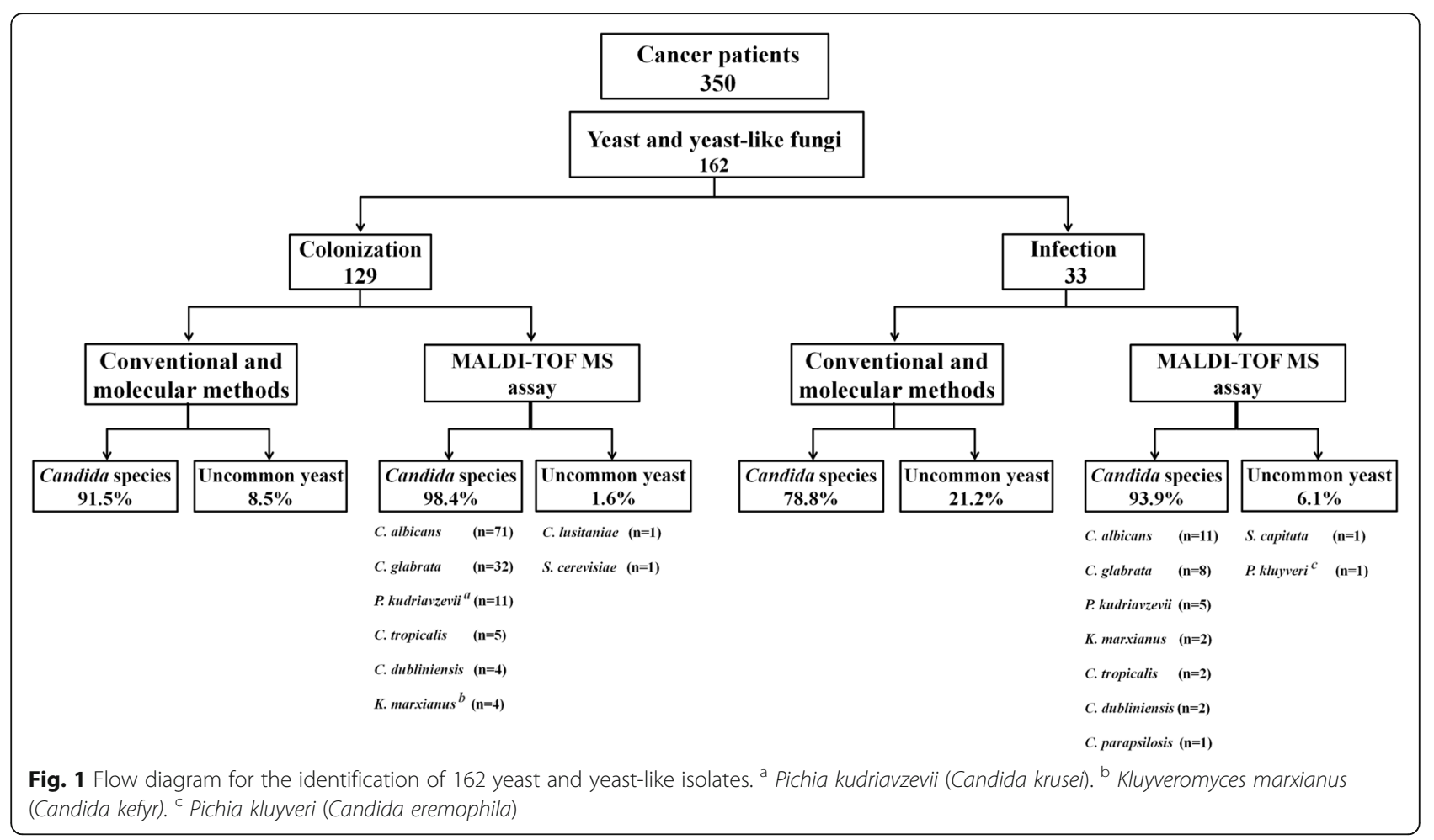

0.008 to $0.5 \mu \mathrm{g} / \mathrm{ml}$, except four isolates of C. glabrata that had a MIC of $1 \mu \mathrm{g} / \mathrm{ml}$ (Tables 3 and 4). Overall in terms of GM MICs, anidulafungin demonstrated potent activity against all isolates $(n=162)$, in comparison with amphotericin $\mathrm{B}$, caspofungin and fluconazole.

\section{Discussion}

Fungal infections caused by Candida species are common in immunocompromised patients, and the incidence has dramatically increased during the last decades [27, 28]. Several virulence factors contribute to the pathogenicity of Candida yeasts, which is one of the main causes of systemic infection in individuals with cancer and contribute to high mortality rates of these patients [29]. Previous studies reported an incidence of oral yeast colonization and infection amongst cancer patients, ranging from $43 \%$ to $90 \%$ and $13 \%$ to $52 \%$, respectively, depending greatly on the type of cancer, regimens to manage the Candida infections, and advance of the disease [6]. In our study we have investigated and compared the yeast colonization and infection rate amongst Iranian cancer patient groups, namely those with hematological malignancies and solid tumors during chemotherapy, as well as their antifungal susceptibilities. On sub-analysis of our study data, it becomes apparent that there is a distinct difference in colonization and infection rate and occurrence of yeast species amongst different types of cancer and different chemotherapy sessions (Table 1 and Fig. 2). The oral yeast colonization rate was $79.6 \%$ and the incidence of oral infections (20.4\%) in our cancer population, which are similar to other studies [6, 30]. Rautema et al. and Schelenz et al. observed similar rates of oral candidiasis during radiotherapy treatment, but this is much lower compared with previously reported studies that reported rates of up to $58 \%[6,31,32]$. It is well known that chemo-radiotherapy can lead to mucositis, xerostomia and damage of the cell mediated immunity which plays an important role in the pathogenesis of oral candidiasis and lead to promotes manifestation of yeast infection $[33,34]$. The oral colonization rate of our hematology patients (38.9\%) had little difference compared with other studies in cancer patients $(49.4 \%$ and $41 \%)$ [6, $32]$. A low oral infection rate $(8 \%)$ was seen in patients with solid tumors although this group had somewhat higher yeast colonization (40.7\%). Patients with hematological malignancies who generally undergo more aggressive chemotherapy leading to a higher degree of generalized immunosuppression, disruption of the mucosal barrier have a subsequent increased risk of infection when compared with solid tumor patients, such as those with prostate cancers. In this group of patients, it is important to emphasize good oral hygiene and prevention of infection. Our study showed that xerostomia and poor oral hygiene are independent risk factors associated with an increased risk of oral yeast colonization. Such association has previously been described in hospitalized elderly patients and is often accompanied with age, compromised nutritional status, presence of dental prosthesis, hyposalivation, and terminal illness $[4,6,35]$. Several studies have 
Table 3 In vitro susceptibilities of 157 clinical isolates to four antifungal agents. MIC range, geometric mean, $\mathrm{MIC}_{50}$, and $\mathrm{MIC}_{90}$ values are expressed in $\mu \mathrm{g} / \mathrm{ml}$

\begin{tabular}{|c|c|c|c|c|c|c|}
\hline \multirow[t]{2}{*}{ (No. of strains) } & \multirow{2}{*}{$\begin{array}{l}\text { Antifungal } \\
\text { agent }\end{array}$} & \multicolumn{5}{|l|}{$\mathrm{MIC} \mu \mathrm{g} / \mathrm{ml}$} \\
\hline & & MIC range & $\mathrm{MIC}_{50}$ & $\mathrm{MIC}_{90}$ & GM & MODE \\
\hline \multirow{4}{*}{$\begin{array}{l}\text { All clinical strains } \\
(n=157)\end{array}$} & Fluconazole & $0.063-64$ & 2 & 8 & 1.65 & 4 \\
\hline & Amphotericin B & $0.016-16$ & 1 & 4 & 0.50 & 1 \\
\hline & Caspofungin & $0.008-8$ & $0.5 \mathrm{mg} / \mathrm{ml}$ & $2 \mu \mathrm{g} / \mathrm{ml}$ & 0.34 & 0.5 \\
\hline & Anidulafungin & $0.008-1$ & 0.063 & 0.5 & 0.06 & 0.063 \\
\hline \multirow[t]{4}{*}{ C. albicans $(n=82)$} & Fluconazole & $0.063-64$ & 0.5 & 8 & 0.80 & 0.5 \\
\hline & Amphotericin B & $0.016-16$ & 1 & 4 & 0.62 & 1 \\
\hline & Caspofungin & $0.008-8$ & 0.25 & 1 & 0.22 & 0.5 \\
\hline & Anidulafungin & $0.008-0.25$ & 0.031 & 0.125 & 0.03 & 0.016 \\
\hline \multirow[t]{4}{*}{ C. dubliniensis $(n=6)$} & Fluconazole & $0.063-0.125$ & 0.125 & 0.125 & 0.11 & 0.125 \\
\hline & Amphotericin B & $0.016-2$ & 0.031 & 2 & 0.09 & 0.031 \\
\hline & Caspofungin & $0.25-2$ & 0.5 & 2 & 0.5 & 0.5 \\
\hline & Anidulafungin & $0.008-0.125$ & 0.125 & 0.25 & 0.07 & 0.016 \\
\hline \multirow[t]{4}{*}{ C. glabrata $(n=40)$} & Fluconazole & $0.25-64$ & 8 & 64 & 7.08 & 4 \\
\hline & Amphotericin B & $0.016-4$ & 1 & 2 & 0.62 & 1 \\
\hline & Caspofungin & $0.008-2$ & 0.5 & 2 & 0.40 & 1 \\
\hline & Anidulafungin & $0.016-1$ & 0.063 & 1 & 0.12 & 1 \\
\hline \multirow{4}{*}{$\begin{array}{l}\text { C. krusei (= Pichia kudriavzevii) } \\
(n=16)\end{array}$} & Fluconazole & $0.25-64$ & 8 & 64 & 7.33 & 4 \\
\hline & Amphotericin B & $0.063-2$ & 0.5 & 1 & 0.59 & 1 \\
\hline & Caspofungin & $0.063-4$ & 2 & 4 & 1.13 & 1 \\
\hline & Anidulafungin & $0.016-0.25$ & 0.125 & 0.25 & 0.07 & 0.25 \\
\hline \multirow[t]{4}{*}{ C. tropicalis $(n=7)$} & Fluconazole & $0.063-8$ & 4 & 8 & 0.63 & 0.063 \\
\hline & Amphotericin B & $0.031-2$ & 1 & 2 & 0.39 & 2 \\
\hline & Caspofungin & $0.031-8$ & 0.5 & 8 & 0.39 & 0.25 \\
\hline & Anidulafungin & $0.008-0.063$ & 0.063 & 0.063 & 0.063 & 0.063 \\
\hline \multirow[t]{4}{*}{ C. kefyr $=($ Kluyveromyces marxianus $)(n=6)$} & Fluconazole & $0.25-32$ & 4 & 32 & 2.82 & 4 \\
\hline & Amphotericin B & $0.016-1$ & 0.5 & 1 & 0.15 & 0.5 \\
\hline & Caspofungin & $0.125-0.05$ & 0.25 & 0.5 & 0.25 & 0.125 \\
\hline & Anidulafungin & $0.031-0.063$ & 0.063 & 0.5 & 0.04 & 0.063 \\
\hline
\end{tabular}

analyzed which Candida species were involved in colonization and infection of cancer patients. A study in Brazil showed that nearly half of the patients (42.9\%) were colonized by C. albicans and $33 \%$ of the patients by nonalbicans species (C. tropicalis, P. kudriavzevii (C. krusei) and C. lusitanae) [36]. The prevalence of Candida species in our study is similar to those mentioned in other reports [37-39]. A recent study by Schelenz et al. reported the distribution of Candida species in 400 patients suffering from hematological malignancies, head neck cancers and solid tumors. These authors found C. albicans (74\%) species followed by C. glabrata (11.5\%), C. tropicalis (2.6\%), C. krusei (2.6\%) and C. parapsilosis (1.9\%) to be involved [6]. Another study showed that approximately $85 \%(n=50)$ of cancer patients were positive for culture of Candida species from the oral mucosa, with $C$. albicans being the most prevalent species, followed by C. glabrata with $14.5 \%$ of cancer patients [29]. Unlike other reports, the uncommon species of S. capitata and P. kluyveri were found to be involved in oral colonization and infection in the current study (Table 1). Other species, including S. cerevisiae, Debaryomyces hansenii (= C. famata) and Clavispora lusitaniae (= C. lusitaniae), have been previously isolated from oral specimens, thereby acting as potential pathogens of oral infection [6,37]. Similar to other studies, the coisolation were seen in $4.9 \%(n=8)$ of our cancer patients. $[6,37]$. Laboratories should be able to detect mixtures of different yeast species in primary cultures because it is an important issue for the management of oral candidiasis patients. In this study emerging species recovered from oral cavity of cancer patients such as $K$. marxianus (C. kefyr), C. parapsilosis, C. tropicalis and P. kudriavzevii (C. krusei) 
Table 4 In vitro susceptibilities of rare clinical species $(n=1)$ to four antifungal agents

\begin{tabular}{lll}
\hline Strains & Antifungal agent & MIC $(\mu \mathrm{g} / \mathrm{ml})$ \\
\hline C. parapsilosis & Fluconazole & 0.25 \\
& Amphotericin B & $0.125 \mu \mathrm{g} / \mathrm{ml}$ \\
& Caspofungin & 4 \\
& Anidulafungin & 0.25 \\
Pichia kluyveri & Fluconazole & 0.5 \\
(Candida eremophila) & Amphotericin B & 1 \\
& Caspofungin & 4 \\
Clavispora lusitaniae & Anidulafungin & 0.25 \\
(Candida lusitaniae) & Fluconazole & 0.5 \\
& Amphotericin B & 0.016 \\
Saccharomyces & Caspofungin & 2 \\
cerevisiae & Anidulafungin & 0.25 \\
& Fluconazole & 0.5 \\
& Amphotericin B & 0.016 \\
Saprochaete capitata & Caspofungin & 4 \\
& Anidulafungin & 0.25 \\
& Fluconazole & 1 \\
& Amphotericin B & 4 \\
& Caspofungin & 0.125 \\
& Anidulafungin & 0.016 \\
\hline
\end{tabular}

were misidentified by conventional methods. This finding may be related to the fact that more reliable techniques are rarely used to identify these species from clinical samples so far. Simple PCR-based analysis using amplicon length differences has been used to identify closely related Candida species in several studies [40]. Recent studies described the use of MALDI-TOF mass spectrometry to discriminate clinical samples [17, 41]. Accordingly, in this study, the simultaneous use of PCR assays and MALDITOF MS turned out to be a powerful technique for the accurate identification of yeasts isolated from the oral cavity.
These findings are in accordance with recent studies showing yeast identification rates of $97.6 \%$ by MALDITOF MS [21, 42]. Similar to other studies, it seems that the incidence of oral candidiasis in cancer patients showed a shift towards non-albicans species probably due to chemotherapy complications, the use of azoles as empirical treatment, or azole prophylaxis [43]. Remarkably, the emergence of non-albicans species was associated with reduced susceptibility to azole antifungal agents it compared with these of common Candida species [18]. A serious concern in cancer patients is that drug resistant isolates may invade the deeper tissues leading to disseminated infection. Therefore, according to the availability of limited data on in vitro antifungal susceptibility values, determination of the antifungal resistance pattern is highly essential before deciding on a specific treatment in order to choose the proper antifungal drug and to predict the outcome of therapy for routine periodic surveillance of fungal infections [11]. Fluconazole is the drug of choice for prophylaxis and treatment of severe candidiasis in cancer patients, but prolonged use of this agent has contributed to the development of drug resistance in Candida isolates $[44,45]$. The resistance rate for fluconazole in the present study was $15.9 \%$ and $12.5 \%$ for C. albicans and C. glabrata, respectively, which is in concordance with other studies [37, 39, 46, 47]. A sub-analysis of our 162 isolates showed that resistance to fluconazole was higher (11.7\%) compared with an UK-based study that indicated a lower resistance rate for fluconazole (4.5\%) [6]. All of the uncommon yeasts were susceptible to fluconazole. In our study, 39\% of yeast strains from cancer patients exhibited higher MIC values to amphotericin $\mathrm{B}$, with $\mathrm{MIC}_{90}$ values of $4 \mu \mathrm{g} / \mathrm{ml}$. Regarding echinocandins, $27.8 \%$ of the Candida isolates were resistant to caspofungin, while all isolates, except C. glabrata (10\%), were highly susceptible to anidulafungin. Unfortunately, we did not have information of recruited cancer patient prior to the initiation of chemotherapy and/or radiotherapy. This could be seen as a comparative data of the effect of chemotherapy and/or radiotherapy on epidemiology of Candida spp.

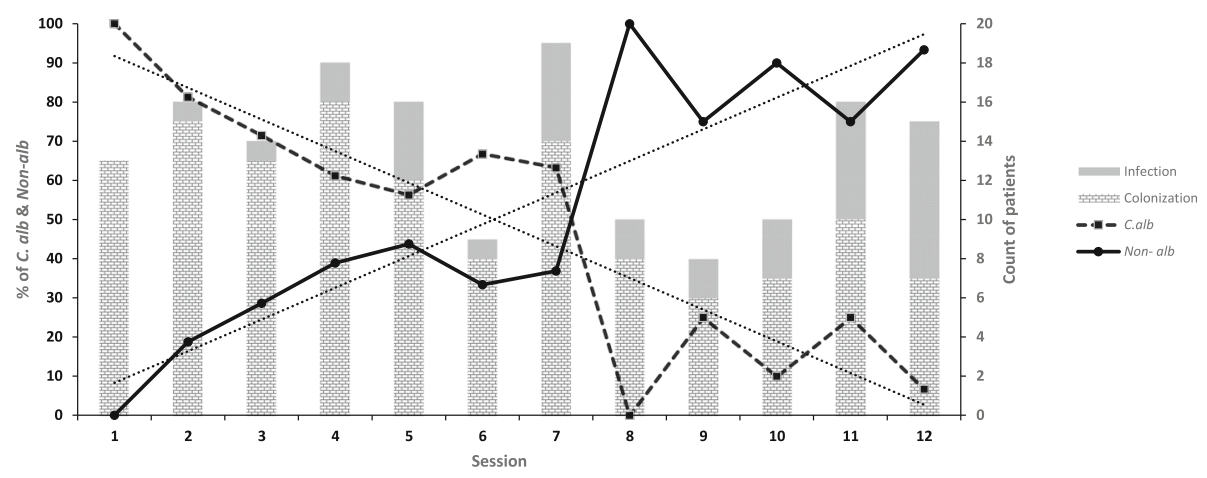

Fig. 2 Distribution of oral colonization and infection by C. albicans and non-albicans Candida among cancer individuals 


\section{Conclusions}

In conclusion, the results showed that non-albicans species and uncommon yeasts are the most common yeast isolates obtained from oral infections from Iranian cancer patients, and C. glabrata and P. kudriavzevii (C. krusei) generally predominate. Overall, the reasons for the emergence of the rare yeast species are not clear, but some medical conditions such as an increase of the number of chemotherapy sessions, the use of azoles as empirical treatment or azole prophylaxis may increase the risk of developing infection caused by these uncommon yeasts. Furthermore, these increases may also be attributed to improvement in the diagnostic methodology e.g., use of MALDI-TOF MS, making it possible to identify such uncommon yeast species. Second, a significant proportion of isolates demonstrated reduced susceptibility to currently used antifungal agents. The study indicates that anidulafungin would be the drug of choice in cancer patients undergoing intensive chemotherapy with documented oral colonization or candidiasis. However, the clinical effectiveness in the treatment of infection and colonization remains to be determined.

\begin{abstract}
Abbreviations
AFG: Anidulafungin; AMB: Amphotericin B; CAN: Acetonitrile;

CFG: Caspofungin; CHROMagar: CHROMagar Candida medium; CLSI: Clinical and Laboratory Standards Institute broth microdilution method; DMSO: Dimethyl sulfoxide; EtOH: Ethanol; FA: Formic acid; Fl: fungal infections; FLU: Fluconazole; GM: Geometric means; HIV: Human Immunodeficiency virus; HSCT: Hematopoietic stem cell transplantation; Hwp1: Hyphal wall protein 1; IFRC: Invasive fungi research center; MALDI: Matrix-assisted laser desorption/ionization; MEA: Malt extract agar; MIC: The minimum inhibitory concentration; MOPS: 3-Nmorpholinepropanesulfonic acid; MS: Mass spectrometry; PCRRFLP: Polymerase chain reaction - restriction fragment length polymorphism; RPMI: Roswell Park Memorial Institute medium; SDA: Sabouraud Dextrose Agar; TOF: Time-of-flight mass
\end{abstract}

\section{Acknowledgements}

The authors are grateful to the all nurses and laboratory technicians at the cancer center of the Mazandaran University Hospital, Sari, Iran for their supportive help during our sampling. We thank Iman Haghani for excellent technical assistance and help with antifungal susceptibility testing.

\section{Funding}

The work of HB was supported by a grant (Nr. 1298) from the School of Medicine, Mazandaran University of Medical Sciences, Sari, Iran, which we gratefully acknowledge.

\section{Availability of data and materials}

The dataset used and analyzed during the current study is available from the corresponding author on reasonable request.

\section{Authors' contributions}

$\mathrm{HB}$ and NA conceived the study. NA and MA prepared the strains and performed phenotypic identification, molecular tests and analyzed the data. SK performed MALDI-TOF assay and JFM interpreted the data. NA, GJ and MB prepared sampling. NA, HB, JFM and TB prepared the manuscript. All authors approved the final version of the manuscript.

\section{Ethics approval and consent to participate}

This study was approved by the ethics committee of Mazandaran University of Medical Sciences, Sari, Iran (Nr. 1298). Written informed consent was obtained from patients for the use of the samples in research.

\section{Consent for publication}

Not applicable.

\section{Competing interests}

No potential conflicts of interest. The authors alone are responsible for the content and writing of the paper.

\section{Publisher's Note}

Springer Nature remains neutral with regard to jurisdictional claims in published maps and institutional affiliations.

\section{Author details}

${ }^{1}$ Student Research Committee, Mazandaran University of Medical Sciences, Sari, Iran. ${ }^{2}$ Department of Medical Mycology and Parasitology, School of Medicine, Mazandaran University of Medical Sciences, Sari, Iran.

${ }^{3}$ Gastrointestinal Cancer Research Center, Mazandaran University of Medica Sciences, Sari, Iran. ${ }^{4}$ Department of Medical Microbiology and Infectious Diseases, Canisius-Wilhelmina Hospital (CWZ), Nijmegen, The Netherlands. ${ }^{5}$ Center of Expertise in Mycology Radboudumc/CWZ, Nijmegen, The Netherlands. ${ }^{6}$ Department of Medical Mycology and Parasitology, Tehran University of Medical Sciences, Tehran, Iran. ${ }^{7}$ Westerdijk Fungal Biodiversity Institute, Utrecht, The Netherlands. ${ }^{8}$ Institute of Biodiversity and Ecosystem Dynamics (IBED), University of Amsterdam, Amsterdam, The Netherlands. ${ }^{9}$ Invasive Fungi Research Center (IFRC), School of Medicine, Mazandaran University of Medical Sciences, Sari, Iran.

Received: 28 June 2017 Accepted: 13 December 2017

Published online: 08 January 2018

References

1. Pfaller MA, Diekema DJ. Epidemiology of invasive candidiasis: a persistent public health problem. Clin Microbiol Rev. 2007;20(1):133-63. https://doi.org/10.1128/CMR.00029-06.

2. Guo F, Yang Y, Kang Y, Zang B, Cui W, Qin B, et al. Invasive candidiasis in intensive care units in China: a multicentre prospective observational study. J Antimicrob Chemother. 2013;68(7):1660-8. https://doi.org/10.1093/jac/ dkt083.

3. Raber-Durlacher JE, Barasch A, Peterson DE, Lalla RV, Schubert MM, Fibbe WE. Oral complications and management considerations in patients treated with high-dose chemotherapy. Support Cancer Ther. 2004;1(4):219-29. https://doi.org/10.3816/SCT.2004.n.014.

4. Fanello S, Bouchara JP, Sauteron M, Delbos V, Parot E, Marot-Leblond A, et al. Predictive value of oral colonization by Candida yeasts for the onset of a nosocomial infection in elderly hospitalized patients. J Med Microbiol. 2006; 55(Pt 2):223-8. https://doi.org/10.1099/jmm.0.46155-0.

5. Jain M, Shah R, Chandolia B, Mathur A, Chauhan Y, Chawda J, et al. The oral carriage of Candida in oral cancer patients of Indian origin undergoing radiotherapy and/or chemotherapy. J Clin Diagn Res. 2016;10(2):ZC17-20. https://doi.org/10.7860/JCDR/2016/15702.7180.

6. Schelenz S, Abdallah S, Gray G, Stubbings H, Gow I, Baker P, et al. Epidemiology of oral yeast colonization and infection in patients with hematological malignancies, head neck and solid tumors. J Oral Pathol Med. 2011;40(1):83-9. https://doi.org/10.1111/j.1600-0714.2010.00937.x.

7. Worthington HV, Clarkson JE, Bryan G, Furness S, Glenny AM, Littlewood A et al. Interventions for preventing oral mucositis for patients with cancer receiving treatment. Cochrane Database Syst Rev. 2011(4):CD000978. doi: https://doi.org/10.1002/14651858.CD000978.pub5.

8. Eddouzi J, Lohberger A, Vogne C, Manai M, Sanglard D. Identification and antifungal susceptibility of a large collection of yeast strains isolated in Tunisian hospitals. Med Mycol. 2013;51(7):737-46. https://doi. org/10.3109/13693786.2013.800239.

9. Miceli MH, Diaz JA, Lee SA. Emerging opportunistic yeast infections. Lancet Infect Dis. 2011;11(2):142-51. https://doi.org/10.1016/S1473-3099(10)70218-8.

10. Vaezi A, Fakhim H, Khodavaisy S, Alizadeh A, Nazeri M, Soleimani A, et al. Epidemiological and mycological characteristics of candidemia in Iran: A systematic review and meta-analysis. J Mycol Med. 2017;27(2):146-152. https://doi.org/10.1016/j.mycmed.2017.02.007.

11. Kathuria S, Singh PK, Sharma C, Prakash A, Masih A, Kumar A, et al. Multidrug-resistant Candida auris misidentified as Candida haemulonii: characterization by matrix-assisted laser desorption ionization-time of flight mass spectrometry and DNA sequencing and its antifungal susceptibility 
profile variability by Vitek 2, CLSI broth microdilution, and Etest method. J Clin Microbiol. 2015;53(6):1823-30. https://doi.org/10.1128/JCM.00367-15 .

12. Cendejas-Bueno E, Kolecka A, Alastruey-Izquierdo A, Theelen B, Groenewald M, Kostrzewa M, et al. Reclassification of the Candida haemulonii Complex as Candida haemulonii (C. haemulonii group I), C. duobushaemulonii sp. nov. (C. haemulonii group II), and C. haemulonii Var. vulnera var. nov.: three multiresistant human pathogenic yeasts. J Clin Microbiol. 2012;50(11):364151. https://doi.org/10.1128/JCM.02248-12

13. De Carolis E, Vella A, Vaccaro L, Torelli R, Posteraro P, Ricciardi W, et al. Development and validation of an in-house database for matrix-assisted laser desorption ionization-time of flight mass spectrometry-based yeast identification using a fast protein extraction procedure. J Clin Microbiol. 2014;52(5):1453-8. https://doi.org/10.1128/JCM.03355-13.

14. Tan KE, Ellis BC, Lee R, Stamper PD, Zhang SX, Carroll KC. Prospective evaluation of a matrix-assisted laser desorption ionization-time of flight mass spectrometry system in a hospital clinical microbiology laboratory for identification of bacteria and yeasts: a bench-by-bench study for assessing the impact on time to identification and cost-effectiveness. J Clin Microbiol. 2012;50(10):3301-8. https://doi.org/10.1128/JCM.01405-12.

15. Cornely OA, Bassetti M, Calandra T, Garbino J, Kullberg BJ, Lortholary O, et al. ESCMID* guideline for the diagnosis and management of Candida diseases 2012: non-neutropenic adult patients. Clin Microbiol Infect. 2012; 18(Suppl 7):19-37. https://doi.org/10.1111/1469-0691.12039.

16. Ullmann AJ, Akova M, Herbrecht R, Viscoli C, Arendrup MC, Arikan-Akdagli S, et al. ESCMID* guideline for the diagnosis and management of Candida diseases 2012: adults with haematological malignancies and after haematopoietic stem cell transplantation (HCT). Clin Microbiol Infect. 2012; 18(Suppl 7):53-67. https://doi.org/10.1111/1469-0691.12041

17. Vlek A, Kolecka A, Khayhan K, Theelen B, Groenewald M, Boel E, et al. Interlaboratory comparison of sample preparation methods, database expansions, and cutoff values for identification of yeasts by matrix-assisted laser desorption ionization-time of flight mass spectrometry using a yeast test panel. J Clin Microbiol. 2014;52(8):3023-9. https://doi.org/10.1128/JCM.00563-14.

18. Capoor MR, Nair D, Deb M, Verma PK, Srivastava L, Aggarwal P. Emergence of non-albicans Candida species and antifungal resistance in a tertiary care hospital. Jpn J Infect Dis. 2005;58(6):344-8.

19. Xu J, Ramos AR, Vilgalys R, Mitchell TG. Clonal and spontaneous origins of fluconazole resistance in Candida albicans. J Clin Microbiol. 2000;38(3):1214-20.

20. Romeo O, Criseo G. Molecular epidemiology of Candida albicans and its closely related yeasts Candida dubliniensis and Candida africana. J Clin Microbiol. 2009;47(1):212-4. https://doi.org/10.1128/JCM.01540-08

21. Bader $\mathrm{O}$, Weig M, Taverne-Ghadwal L, Lugert R, Gross U, Kuhns M. Improved clinical laboratory identification of human pathogenic yeasts by matrixassisted laser desorption ionization time-of-flight mass spectrometry. Clin Microbiol Infect. 2011;17(9):1359-65. https://doi.org/10.1111/j.1469-0691. 2010.03398.x.

22. Marklein G, Josten M, Klanke U, Muller E, Horre R, Maier T, et al. Matrixassisted laser desorption ionization-time of flight mass spectrometry for fast and reliable identification of clinical yeast isolates. J Clin Microbiol. 2009; 47(9):2912-7. https://doi.org/10.1128/JCM.00389-09.

23. CLSI. Reference method for broth dilution antifungal susceptibility testing of yeasts; approved standard-third edition, M27-A3. Wayne: CLSI; 2008.

24. Clinical and Laboratory Standards Institute (CLSI). Reference method for broth dilution antifungal susceptibility testing of yeasts: fourth informational supplement M27-S4. Wayne: CLSI; 2012.

25. Pfaller MA, Boyken LB, Hollis RJ, Kroeger J, Messer SA, Tendolkar S, et al. Validation of 24-hour fluconazole MIC readings versus the CLSI 48-hour broth microdilution reference method: results from a global Candida antifungal surveillance program. J Clin Microbiol. 2008;46(11):3585-90. https://doi.org/10.1128/JCM.01391-08.

26. Pfaller MA, Boyken LB, Hollis RJ, Kroeger J, Messer SA, Tendolkar S, et al. Validation of 24-hour posaconazole and voriconazole MIC readings versus the CLSI 48-hour broth microdilution reference method: application of epidemiological cutoff values to results from a global Candida antifungal surveillance program. J Clin Microbiol. 2011;49(4): 1274-9. https://doi.org/10.1128/JCM.02437-10.

27. Kofteridis DP, Lewis RE, Kontoyiannis DP. Caspofungin-non-susceptible Candida isolates in cancer patients. J Antimicrob Chemother. 2010;65(2): 293-5. https://doi.org/10.1093/jac/dkp444.

28. Fesharaki SH, Haghani I, Mousavi B, Kargar ML, Boroumand M, Anvari MS, et al. Endocarditis due to a co-infection of Candida albicans and Candida tropicalis in a drug abuser. J Med Microbiol. 2013;62(Pt 11):1763-7. https:// doi.org/10.1099/jmm.0.060954-0.

29. de Sousa LV, Santos VL, de Souza Monteiro A, Dias-Souza MV, Marques SG, de Faria ES, et al. Isolation and identification of Candida species in patients with orogastric cancer: susceptibility to antifungal drugs, attributes of virulence in vitro and immune response phenotype. BMC Infect Dis. 2016; 16:86. https://doi.org/10.1186/s12879-016-1431-4.

30. Jham BC, Reis PM, Miranda EL, Lopes RC, Carvalho AL, Scheper MA, et al. Oral health status of 207 head and neck cancer patients before, during and after radiotherapy. Clin Oral Investig. 2008;12(1):19-24. https://doi.org/10.1007/s00784007-0149-5.

31. Rautemaa R, Rusanen P, Richardson M, Meurman JH. Optimal sampling site for mucosal candidosis in oral cancer patients is the labial sulcus. J Med Microbiol. 2006;55(Pt 10):1447-51. https://doi.org/10.1099/jmm.0.46615-0.

32. Epstein JB, Hancock PJ, Nantel S. Oral candidiasis in hematopoietic cell transplantation patients: an outcome-based analysis. Oral Surg Oral Med Oral Pathol Oral Radiol Endod. 2003;96(2):154-63. https://doi.org/10.1016/ S1079210403002968

33. Grotz KA, Genitsariotis S, Vehling D, Al-Nawas B. Long-term oral Candida colonization, mucositis and salivary function after head and neck radiotherapy. Support Care Cancer. 2003;11(11):717-21. https://doi. org/10.1007/s00520-003-0506-0.

34. Soysa NS, Samaranayake LP, Ellepola AN. Cytotoxic drugs, radiotherapy and oral candidiasis. Oral Oncol. 2004;40(10):971-8. https://doi.org/10. 1016/j.oraloncology.2003.12.013.

35. Butticaz G, Zulian GB, Preumont M, Budtz-Jorgensen E. Evaluation of a nystatin-containing mouth rinse for terminally ill patients in palliative care. $J$ Palliat Care. 2003;19(2):95-9.

36. Jham BC, Franca EC, Oliveira RR, Santos VR, Kowalski LP, da Silva Freire AR. Candida oral colonization and infection in Brazilian patients undergoing head and neck radiotherapy: a pilot study. Oral Surg Oral Med Oral Pathol Oral Radiol Endod. 2007;103(3):355-8. https://doi.org/ 10.1016/j.tripleo.2006.02.005

37. Sanchez-Vargas LO, Ortiz-Lopez NG, Villar M, Moragues MD, Aguirre JM, Cashat-Cruz M, et al. Oral Candida isolates colonizing or infecting human immunodeficiency virus-infected and healthy persons in Mexico. J Clin Microbiol. 2005;43(8):4159-62. https://doi.org/10.1128/JCM.43.8. 4159-4162.2005.

38. Leung WK, Dassanayake RS, Yau JY, Jin L, Yam WC, Samaranayake LP. Oral colonization, phenotypic, and genotypic profiles of Candida species in irradiated, dentate, xerostomic nasopharyngeal carcinoma survivors. J Clin Microbiol. 2000;38(6):2219-26.

39. Belazi M, Velegraki A, Koussidou-Eremondi T, Andreadis D, Hini S, Arsenis G, et al. Oral Candida isolates in patients undergoing radiotherapy for head and neck cancer: prevalence, azole susceptibility profiles and response to antifungal treatment. Oral Microbiol Immunol. 2004;19(6):347-51. https://doi. org/10.1111/j.1399-302x.2004.00165.x.

40. Yazdanparast SA, Khodavaisy S, Fakhim H, Shokohi T, Haghani I, Nabili M, et al. Molecular characterization of highly susceptible Candida africana from vulvovaginal candidiasis. Mycopathologia. 2015;180(5-6):317-23. https://doi. org/10.1007/s11046-015-9924-z .

41. Taj-Aldeen SJ, AbdulWahab A, Kolecka A, Deshmukh A, Meis JF, Boekhout T. Uncommon opportunistic yeast bloodstream infections from Qatar. Med Mycol. 2014;52(5):552-6. https://doi.org/10.1093/mmycol/myu016.

42. Sendid B, Ducoroy P, Francois N, Lucchi G, Spinali S, Vagner O, et al. Evaluation of MALDI-TOF mass spectrometry for the identification of medically-important yeasts in the clinical laboratories of Dijon and Lille hospitals. Med Mycol. 2013; 51(1):25-32. https://doi.org/10.3109/13693786.2012.693631.

43. Saghrouni FBI, Ben Abdeljelil J, Yacoub A, Khammari I, Fathallah A. et, al. Epidemiological trends in invasive candidiasis: results from a 15 year study in Sousse region Tunisia. J Mycol Med. 2011;21:123-9.

44. Badiee P, Badali H, Boekhout T, Diba K, Moghadam AG, Hossaini Nasab A, et al. Antifungal susceptibility testing of Candida species isolated from the immunocompromised patients admitted to ten university hospitals in Iran: comparison of colonizing and infecting isolates. BMC Infect Dis. 2017;17(1): 727. https://doi.org/10.1186/s12879-017-2825-7.

45. Fakhim H, Emami S, Vaezi A, Hashemi SM, Faeli L, Diba K, et al. In Vitro Activities of Novel Azole Compounds ATTAF-1 and ATTAF-2 against Fluconazole-Susceptible and -Resistant Isolates of Candida Species. Antimicrob Agents Chemother. 2016;61(1). https://doi.org/10.1128/AAC. 01106-16. 
46. Jayachandran AL, Katragadda R, Thyagarajan R, Vajravelu L, Manikesi S, Kaliappan S, et al. Oral Candidiasis among cancer patients attending a tertiary Care Hospital in Chennai, South India: an evaluation of Clinicomycological association and antifungal susceptibility pattern. Can J Infect Dis Med Microbiol. 2016;2016:8758461. https://doi.org/10.1155/2016/ 8758461.

47. Al-Abeid HM, Abu-Elteen $\mathrm{KH}$, Elkarmi AZ, Hamad MA. Isolation and characterization of Candida spp. in Jordanian cancer patients: prevalence, pathogenic determinants, and antifungal sensitivity. Jpn J Infect Dis. 2004; 57(6):279-84.

Submit your next manuscript to BioMed Central and we will help you at every step:

- We accept pre-submission inquiries

- Our selector tool helps you to find the most relevant journal

- We provide round the clock customer support

- Convenient online submission

- Thorough peer review

- Inclusion in PubMed and all major indexing services

- Maximum visibility for your research

Submit your manuscript at www.biomedcentral.com/submit
Biomed Central 